\title{
Predictive Factors of Renal Function in Partial Laparoscopic Nephrectomy in Patients with a Kidney Tumor
}

\author{
Miguel E. Jimenez-Romero ${ }^{\mathrm{a}, \mathrm{b}} \quad$ Jose C. Moreno-Cortes ${ }^{\mathrm{b}} \quad$ Elba Y. Canelon-Castillo ${ }^{\mathrm{a}}$ \\ Sara Diez-Farto ${ }^{a}$ Jose D. Santotoribio ${ }^{c, d}$ \\ aDepartment of Urology, Puerto Real University Hospital; bepartment of Surgery, Cadiz University School of Medicine; \\ 'Department of Laboratory Medicine, Puerto Real University Hospital; dDepartment of Biomedicine, Biotechnology and Public Health, \\ Cadiz University School of Medicine, Cadiz, Spain
}

\section{Key Words}

Ischemia $\cdot$ Nephron-sparing surgery • Partial nephrectomy • Renal cell carcinoma $\cdot$ Renal function

\section{Abstract}

Background: Laparoscopic partial nephrectomy has proven to be an ideal option for tumors in initial stages, preserving part of the renal parenchyma and reducing the possible risk of glomerular filtration decrease. Objectives: The main objective of this study is to determine the factors that can influence, to a greater extent, renal function deterioration after surgery. Methods: This is an observational, descriptive and longitudinal study. The renal funct ion was calculated using the Chronic Kidney Disease Epidemiology Collaboration formula, and patients were divided into 2 groups depending on whether or not their renal function had been affected after surgery. We studied the correlation between the decrease of renal function and other variables. Results: The sample comprised 48 patients. In 30 of these cases, renal function had deteriorated after surgery. We observed a statistically significant relationship between the weight of the patient ( $p$ $=0.0230)$, size of the tumor $(p=0.0035)$, ischemic time ( $p$ $=0.0287)$, duration of the surgery $(p=0.0297)$, the RENAL score $(p=0.0230)$ and renal function deterioration. Conclusions: Partial laparoscopic nephrectomy is associated with a deterioration in renal function, where there is a decrease in glomerular filtration after surgery. The deterioration will

\section{KARGER}

Fax +41613061234

E-Mail karger@karger.com

www.karger.com
(C) 2019 The Author(s)

Published by S. Karger AG, Basel Upen access

This article is licensed under the Creative Commons AttributionNonCommercial-NoDerivatives 4.0 International License (CC BYNC-ND) (http://www.karger.com/Services/OpenAccessLicense). $\mathrm{NC}-\mathrm{ND}$ ) (http://www.karger.com/Services/OpenAccessLicense).
Usage and distribution for commercial purposes as well as any distribution of modified material requires written permission. depend on the weight of the patient, size of the tumour, ischemic time and duration of the surgery. The RENAL score can be used to predict said deterioration.

(c) 2019 The Author(s)

Published by S. Karger AG, Basel

\section{Introduction}

Kidney cell cancer accounts for 2-3\% of all cancers [1], primarily affecting Western countries. The standardized use of imaging scans in the last few years, together with technical advances, have led to an increased incidence of kidney tumors being discovered incidentally and at earlier stages [2, 3]. Laparoscopic partial nephrectomy (LPN) has become the standardized surgical treatment for T1a $(<4 \mathrm{~cm})$ kidney tumors and some T1b (4-7 $\mathrm{cm}$ ) correctly selected tumors [4]. LPN has advantages over the open nephrectomy, such as a decrease in surgery time, less blood loss and less post-operative pain medication expenditure, as well as a shorter hospital stay and recovery time. However, it seems to lead to higher post-operative complications, requiring longer warm ischemic time with the corresponding renal function deterioration. Nonetheless, different studies have shown less risk of chronic kidney disease and cardiovascular events after LPN, with a noteworthy improvement in the overall survival rate $[5,6]$. 
The renal function evaluation can be calculated by analyzing the glomerular filtration rate (GFR) and by using predictive equations. Consensus documents from scientific societies recommend the use of the Chronic Kidney Disease Epidemiology Collaboration formula (CKD-EPI) for the estimation of the GFR [7]. Using the difference between the baseline or pre-operative GFR and the post-operative GFR, we can determine whether the patient has suffered renal function deterioration (RFD) after the LPN. In the case of these patients, the GFR will be lower than the baseline GFR.

One of the main purposes should be to limit, where possible, the loss of renal function associated with a LPN. Although RFD has been connected to the percentage of preserved kidney and the warm ischemic time [810], several factors can influence the RFD after a LPN, such as pre-operative [weight, height, patient body mass index (BMI) and size of the tumor mass], intra-operative (length of the surgery, warm ischemic time and bleeding) and post-operative factors (tumor histopathology, Furhman grade, surgical margin, bleeding and fistula). Currently, we use different anatomic classifications [radius, exophytic/endophytic, nearness, anterior/posterior, location (RENAL) and Arterial Based Complexity (ABC) scores] [11, 12], which have been developed for the preoperative evaluation of the complexity and characteristics of the tumor, in order to provide the best possible treatment and approach for RFD after a LPN.

The objective of this study is to determine the factors associated with RFD after a LPN in patients with kidney tumors.

\section{Materials and Methods}

\section{Design}

This is a retrospective, observational, descriptive and longitudinal study. We have followed the ethical recommendations of the Declaration of Helsinki (Fortaleza, 2013), approved by the Cadiz Ethics of Research Committee. All the participants in this study have signed an informed consent form.

\section{Patients}

Some Caucasian patients with kidney tumors that underwent a LPN in the Puerto Real University Hospital between January 2012 and November 2017 are included in this study.

\section{Studied Variables}

Dependent variable is renal function after partial nephrectomy. The renal function was evaluated by analyzing the GFR. The GFR was calculated before (GFRb) and after the operation (GFRp). Patients were classified into 2 groups considering renal function after the operation: patients who had preserved their renal func- tion $(\mathrm{GFRp} \geq \mathrm{GFRb})$ and patients with RFD (GFRp $<$ GFRb). The GFR was calculated via the Chronic Kidney Disease Epidemiology Collaboration formula, using the age, gender and serum creatinine concentration of the patient [1]. The serum creatinine level was determined using the Hitachi Modular cobas c 702 (Roche Diagnostics) analyser.

Pre-operative independent variables are gender, age, weight, height, BMI, radiological size of the tumor mass, ABC Classification and RENAL Classification. Intra-operative independent variables are surgery duration, warm ischemic time, intra-operative bleeding and the need of transition to open surgery. Post-operative independent variables are histopathology of the tumor, Furhman grade, surgical margin, post-operative bleeding and fistula.

\section{Statistical Analysis}

Data were processed using the statistical program MedCalc ${ }^{\circledR}$, with a significance level of 0.05 . The quantitative variables underwent the D'Agostino-Pearson test to determine whether or not they had a normal distribution (Gaussian). For the descriptive analysis, we used the qualitative variable frequencies, the arithmetic mean and range of the quantitative variables at normal distribution, and the median and range of the quantitative variables at non-Gaussian distribution. The comparison within the groups of qualitative variables was calculated by the Chi-square test, while the one between the quantitative variables with normal distribution was calculated by Student's $t$-test. As for the quantitative variables with non-Gaussian distribution, we used the Wilcoxon test for paired samples and Mann-Whitney's U test for independent samples. We calculated the diagnostic precision for each of the independent variables to predict the RFD using the receiver operating characteristics (ROC) curves, calculating the area under the curve (AUC), as well as the optimal cut-off point mapping its corresponding sensitivity and specificity. We considered the optimal cut-off point to be that of higher sensitivity with high specificity $(>80 \%)$, in order to reduce the number of false positives.

\section{Results}

A total of 48 patients were studied, 10 women and 38 men, in which 18 patients $(37.5 \%)$ preserved their renal function and $30(62.5 \%)$ presented with post-operative deterioration. The follow-up time was between 2 and 78 months (median: 25 and interquartile range: 33 months). All the quantitative variables presented a non-Gaussian distribution.

Table 1 shows the evaluation of renal function of the patients included in this study. A decrease in the GFR is presented after the surgery (median GFRb $65.0 \mathrm{ml} / \mathrm{min}$ and median GFRp $=49.5 \mathrm{ml} / \mathrm{min}$ ). Using the Wilcoxon test for paired samples within the GFRb and GFRp variables, statistically significant differences between them were obtained $(\mathrm{p}=0.0061)$. RFD patients presented a decrease in GFR with a median of $-19.3 \mathrm{ml} / \mathrm{min}$.

Table 2 shows the descriptive statistics of the independent variables and the differences existing between the 2 groups of patients. We concluded that 5 independent 
Table 1. Descriptive statistics (median and range) of the serum creatinine concentration levels and of the GFR before and a month after the LPN

\begin{tabular}{lccr}
\hline & $\begin{array}{c}\text { All the patients } \\
(\mathrm{n}=48)\end{array}$ & $\begin{array}{c}\text { Patients without RFD } \\
(\mathrm{n}=18)\end{array}$ & $\begin{array}{c}\text { Patients with RFD } \\
(\mathrm{n}=30)\end{array}$ \\
\hline Baseline creatinine, $\mathrm{mg} / \mathrm{dl}$ & $1.00(0.52-6.10)$ & $1.10(0.52-6.10)$ & $0.89(0.67-1.90)$ \\
GFRb, ml/min & $65.0(6.7-104.7)$ & $57.8(6.7-103.3)$ & $81.3(25.8-104.7)$ \\
Post-operative creatinine, $\mathrm{mg} / \mathrm{dl}$ & $1.20(0.40-5.99)$ & $0.95(0.40-5.99)$ & $1.30(0.72-2.30)$ \\
GFRp, ml/min & $49.5(6.8-150.7)$ & $75.3(6.8-150.7)$ & $43.1(20.0-98.0)$ \\
GFRp - GFRb, ml/min & $-6.48(-70.6-73.2)$ & $6.88(0-73.2)$ & $-19.3(-70.6--2.1)$ \\
\hline
\end{tabular}

variables were significantly linked to the RFD associated with the surgery. Three variables were pre-operative: weight of the patient $(p=0.0230)$, tumor size $(p=$ $0.0035)$, and the RENAL classification $(p=0.0230)$. The other 2 variables were intra-operative: warm ischemic time $(\mathrm{p}=0.0287)$ and the duration of the surgery $(\mathrm{p}=$ 0.0297).

The ROC curves were calculated for the 4 independent quantitative variables statistically linked, in a significant way, with the RFD (fig. 1). The AUC obtained and the optimal cut-off points mapping its corresponding sensitivity and specificity were shown in table 3 . Using very specific cut-off points, we observed that patients weighing more than $84 \mathrm{~kg}$, with a tumor size $>4 \mathrm{~cm}$, ischemic time higher than 26 minutes or surgery lasting longer than 200 minutes, presented a high probability of RFD after the surgery.

\section{Discussion}

The analysis of this series of patients shows that LPN is significantly associated with RFD. LPN has become the standard surgical treatment for pT1 renal tumors. Different retrospective works have shown that at this stage of tumor development, survival is similar either taking the partial nephrectomy approach or the radical nephrectomy one [13]. But it can preserve a better renal function when performing a nephron-sparing surgery, which reduces the risk of metabolic or cardiovascular disorders $[14,15]$. Therefore, one of the main objectives of LPN is to limit the loss of renal function linked to this technique. In the last few years, several studies have focused on the analysis of the variables that could alter the GFR. The quantity and quality of the preserved renal parenchyma are the two fundamental aspects that will determine the post-operative renal function, which in turn will depend on other factors such as tumor size and warm ischemic time. In this series of patients, we observed that RFD depended on tumor size, warm ischemic time, duration of the surgery and weight of the patient.

During the nephron-sparing surgery, clamping the renal artery allows for interruption of kidney blood flow during the surgery, which enables the surgeon to work on an area with less bleeding. However, some authors support that blood flow interruption can lead to ischemic damage of the preserved tissue; while others state that the kidney can support it. Until now, the importance of warm ischemia has generated controversy, although studies increasingly show its harmful effect on the kidney. In this study we observed that the ischemic time $(p=0.0287)$ is significantly linked to RFD after surgery. In the group of patients with RFD, the median ischemic time was longer by 2.5 minutes than in the patients without RFD (table 2 ). Using the Volpe et al. [7] meta-analysis, we conducted a systematic review which included a total of 96 works, with the objective of showing renal function predictive factors after the surgical resection of kidney tumors using LPN. They conclude that a better post-operative renal function is associated with a clamping time below 25 minutes. Martin et al. [16] carried out a similar study, in which they reviewed 94 works in order to determine the factors that are linked to a higher RFD after a LPN, among which was the prolonged ischemic time. Inside study, they state that if the ischemic time is longer than 25 minutes, approximately every extra minute increases the risk of the kidney suffering RFD by about 5-6\%. In this study, we obtained an optimal cut-off point of ischemic time to predict RFD after LPN of 26 minutes, which is similar to the meta-analysis published and $89.9 \%$ of the patients with a longer ischemic time than 26 minutes presented with RFD (table 3). 
Table 2. Descriptive statistic (frequency or median and range) of the independent variables and the statistical differences between the patients with and without RFD after the LPN

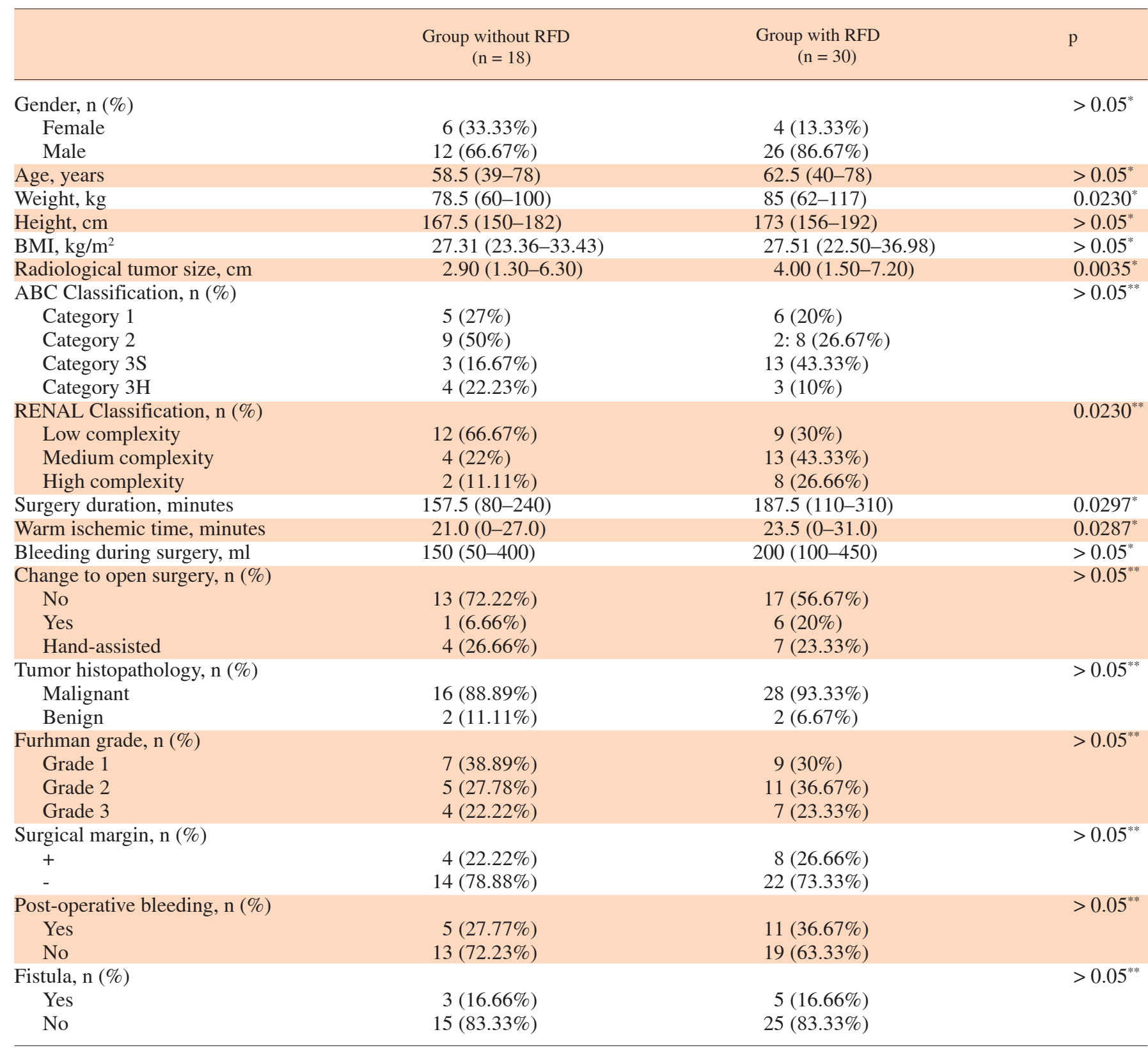

"Mann-Whitney's U test; **Chi-square test.

The preserved renal parenchyma volume is another of the variables that different analysis have associated with RFD. In the study of Martin et al. [16] they support that the more renal tissue preserved, the better the renal function results will be, and the longer the time interval until it becomes a chronic condition. Conversely, Marconi et al. [17] carried out a review with the same objective, analyzing the surgical factors that affect renal function. They reached the same conclusion, to the point of considering that the amount of preserved tissue is the variable with the most incidence in RFD. They also stipulate that the amount of tissue preserved is mainly dependent on the 


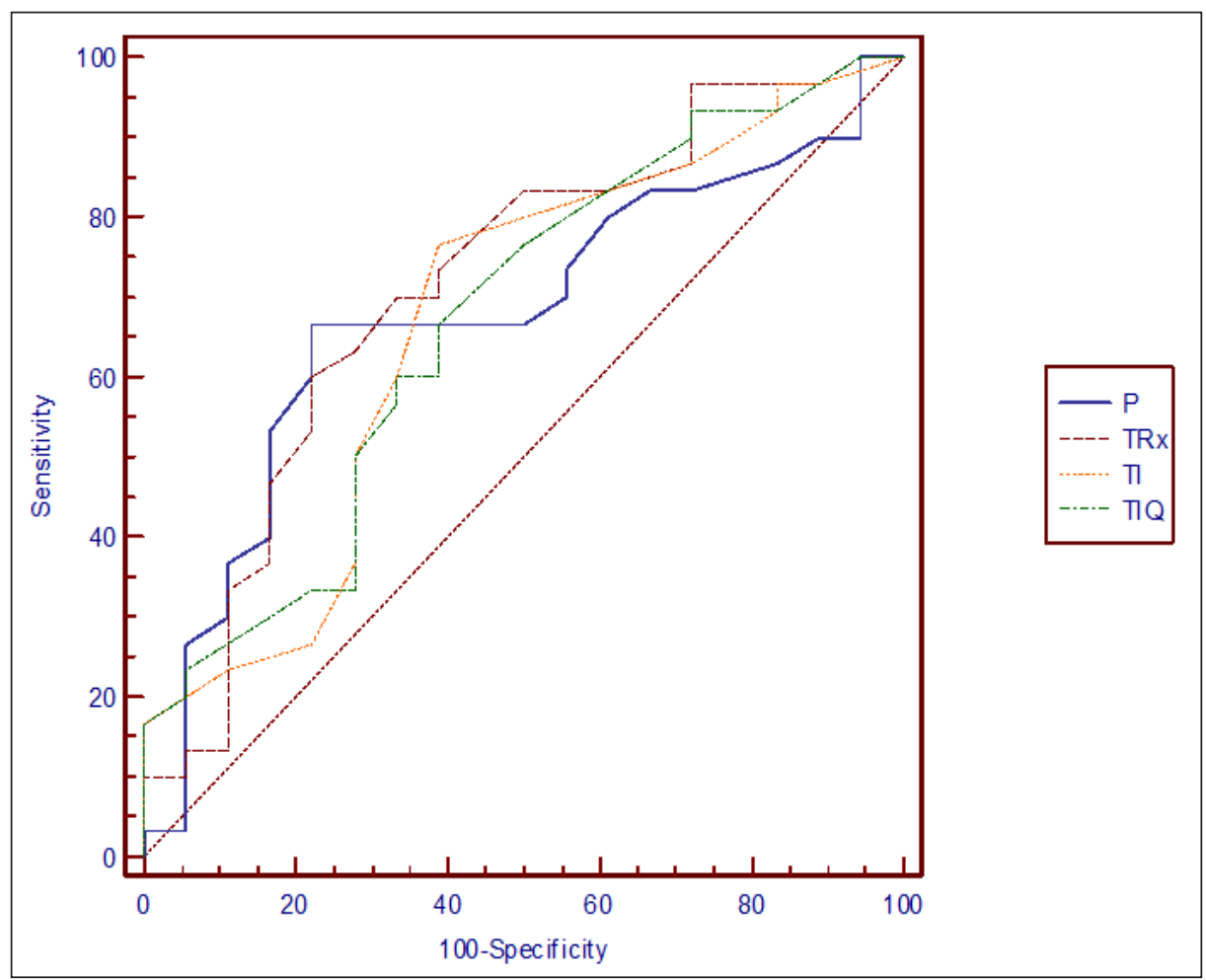

Fig. 1. ROC curves of the quantitative independent variables linked to renal function deterioration after laparoscopic partial nephrectomy $(\mathrm{P}=$ Body weight; $\mathrm{TRx}=$ radiological kidney tumor size; TI = ischemic time; TIQ = surgery time).

Table 3. AUC, optimal cut-off points, sensitivity and specificity of the quantitative independent variables to predict RFD after a LPN

\begin{tabular}{|c|c|c|c|c|}
\hline & AUC $(95 \% \mathrm{CI})$ & Cut-off & Sensitivity (95\% CI) & Specificity $(95 \%$ CI) \\
\hline Body weight & $0.677(0.526-0.804)$ & $>84 \mathrm{~kg}$ & $53.3 \%(34.3-71.6)$ & $83.3 \%(58.6-96.2)$ \\
\hline Ischemic time & $0.671(0.521-0.800)$ & $>26$ minutes & $23.3 \%(10.0-42.3)$ & $88.9 \%(65.2-98.3)$ \\
\hline Surgery time & $0.670(0.520-0.799)$ & $>200$ minutes & $30.0 \%(14.8-49.4)$ & $83.3 \%(58.6-96.2)$ \\
\hline
\end{tabular}

$\mathrm{CI}=$ Confidence interval

size of the tumor, as well as on other surgical factors. Similarly, within our study, we confirm that the size of the tumor, and therefore the amount of resected renal tissue, correlates with the RFD after the LPN ( $p=0.0035)$. The median size of the tumors in deteriorative patients was $1.10 \mathrm{~cm}$ larger than in patients without RFD (table 2).
The weight (overweight and obese) $(\mathrm{p}=0.0230)$ is the third variable within our series, which has a significant incidence on RFD. The median weight in patients with RFD was $85 \mathrm{~kg}$, versus $78.5 \mathrm{~kg}$ in the group without RFD. Although it is not a factor with as much solid evidence as the previous ones, this association has been 
described in other studies. Praga et al. [18] carried out a cross-sectional study with the objective of analyzing the risk factors related to the development of renal deficiency and proteinuria after a nephrectomy. They included a total of 73 patients without proteinuria and with preserved renal function at the time of surgery. They found that the patients who suffered RFD and proteinuria development, on average, weighed $17 \mathrm{~kg}$ more than those who suffered no such alteration. Malcom et al. [19] retrospectively analyzed the weight prognostic factor and the BMI in 388 patients who had undergone surgery due to kidney cancer. They also concluded that obesity is a risk factor which contributes to the development of renal deficiency in patients who have undergone a LPN, especially within the first 10 years after the surgery. Additionally, this factor considerably increased morbidity.

Lastly, the duration of the surgery is another factor that seems to significantly influence RFD. Within our study, the group of patients with RFD had a surgery that was more than 30 minutes on average $(p=0.0230)$. We have found no scientific research studies in which this association has been described. The duration of the surgery is greatly linked to the previously described variables, as the excess of fatty tissue presented in obese patients and larger tumors are factors that can increase the complexity of the surgery, which in turn, requires a longer surgery time.

During the last few years, several score systems used before carrying out a LPN have been developed, with the objective of providing tools that may allow us to predict the complexity of the surgery, the risk of peri-operative complications, and oncological results in some cases. More specifically, the RENAL system [20] allows for classification of renal mass complexity into 3 levels, grouping the 5 characteristics obtained though imaging studies (radius of the tumor, exophytic or endophytic properties of the tumor, proximity to the collecting system, anterior/posterior location and location relative to the polar line). In 2015 the Memorial Sloan Kettering Cancer Center [11] developed the ABC scoring system. An intuitive and practical system which takes into consideration the relationship between the depth of the tumor and the vascular anatomy of the renal artery, particularly, the arterial branches will be dissected. Thus, 4 categories are established in relation to tumor complexity, from low to high complexity: category 1 (interlobular arteries that arch), category 2 (interlobular arteries), category $3 \mathrm{~S}$ (segmental arteries), and category $3 \mathrm{H}$ (hilar vessels).

After analyzing the RFD prognostic ability of both systems within our series, we found that the RENAL scale could significantly predict RFD ( $p=0.0230$ ); yet we did not find any association between this deterioration and the scores of the ABC classification ( $\mathrm{p}=$ 0.1957). Kriegmair et al. [21] carried out a retrospective study with a series of 305 patients, with the objective of comparing 4 renal mass classification systems: the RENAL system, the PADUA system, the NePhRO system and the C-Index system. They observed that the RENAL system can be used to significantly predict not only the complexity and complications of the surgery, but also the ischemic time and the RFD. When Spaliviero et al. [20] developed the $\mathrm{ABC}$ system and published the results, they highlighted its highly accurate capacity to predict surgical complications (hemorrhage and fistulas), as well as the necessary ischemic time. Yet, as the case in our study, the different classification degrees were not linked to RFD after surgery. Hence, it seems that the RENAL scale is better than the ABC scale when it comes to predicting post-operative RFD.

Naturally, our study has its limitations. Besides those derived from the type of study itself, we have analyzed a series of cases, some of which were operated on quite recently. Thus, not all the subjects had the same follow-up time: some of them had years and some were months. That is why we analyze how surgery affected renal function, only bearing in mind the GFR a month after surgery, a determined variable in all subjects included in this study. One month after surgery, in 11 of the 30 patients in whom there was RFD, we observed a slow and progressive improvement of the RFD as months went by, with an average increase of GFR of $9.7 \mathrm{ml} / \mathrm{min}$ after a year, although they did not recover the renal function existing before surgery.

\section{Conclusion}

We conclude that LPN is linked to RFD, causing a decreasing glomerular filtration after surgery. The RFD will depend on the patient's weight, the radiological size of the tumor, the ischemic time during surgery and the length of said surgery. The RENAL score can predict RFD after LPN. 


\section{References}

1 European Network of Cancer Registries: Eurocim version 4.0. 2001, Lyon, France.

2 Doeuk N, Guo D, Haddad R, Lau H, Woo $\mathrm{HH}$, Bariol S, Drummond M, Vladica P, Brooks A, Patel MI: Renal cell carcinoma: stage, grade and histology migration over the last 15 years in a large Australian surgical series. BJU Int 2010;107:1381-1385.

3 Capitanio U, Montorsi F: Renal cancer. Lancet 2016;387:894-906.

4 Becker F, Siemer S, Hack M, Humke U, Ziegler M, Stockle M: Excellent long-term cancer control with elective nephron-sparing surgery for selected renal cell carcinomas measuring more than $4 \mathrm{~cm}$. Eur Urol 2006; 49:1058-1064.

5 Go AS, Chertow GM, Fan D, McCulloch CE, Hsu CY: Chronic kidney disease and the risks of death, cardiovascular events, and hospitalization. N Engl J Med 2004;351:1296-1305.

6 Weight CJ, Larson BT, Fergany AF, Gao T, Lane BR, Campbell SC, Kaouk JH, Klein EA, Novick AC: Nephrectomy induced chronic renal insufficiency is associated with increased risk of cardiovascular death and death from any cause in patients with localized cT1b renal masses. J Urol 2010; 183:1317-1323.

7 Alcázar R, Egocheaga MI, Orte L, Lobos JM, González Parra E, Alvarez Guisasola F, Górriz JL, Navarro JF, Martín de Francisco AL: SEN-SEMFYC consensus document on chronic kidney disease. Nefrologia 2008; 28:273-282.

8 Volpe A, Blute ML, Ficarra V, Gill IS, Kutikov A, Porpiglia F, Rogers C, Touijer KA, Van Poppel H, Thompson RH: Renal ischemia and function after partial nephrectomy: a collaborative review of the literature. Eur Urol 2015;68:61-74.
9 Porpiglia F, Fiori C, Bertolo R, Morra I, Russo R, Piccoli G, Angusti T, Podio V: Long-term functional evaluation of the treated kidney in a prospective series of patients who underwent laparoscopic partial nephrectomy for small renal tumors. Eur Urol 2012;62:130-135.

10 Buffi N, Lista G, Larcher A, Lughezzani G, Ficarra V, Cestari A, Lazzeri M, Guazzoni G: Margin, ischemia, and complications (MIC) score in partial nephrectomy: a new system for evaluating achievement of optimal outcomes in nephron-sparing surgery. Eur Urol 2012;62:617-618.

11 Klatte T, Ficarra V, Gratzke C, Kaouk J, Kutikov A, Macchi V, Mottrie A, Porpiglia F, Porter J, Rogers CG, Russo P, Thompson RH, Uzzo RG, Wood CG, Gill IS: A literature review of renal surgical anatomy and surgical strategies for partial nephrectomy. Eur Urol 2015;68:980-992.

12 Spaliviero M, Poon BY, Karlo CA, Guglielmetti GB, Di Paolo PL, Beluco Corradi R, Martin-Malburet AG, Campos-Juanatey F, Escudero-Fontano E, Sjoberg DD, Russo P, Coleman JA, Akin O, Touijer KA: An arterial based complexity (ABC) scoring system to assess the morbidity profile of partial nephrectomy. Eur Urol 2016;69:72-79.

13 Van Poppel H, Da Pozzo L, Albrecht W, Matveev V, Bono A, Borkowski A, Colombel M, Klotz L, Skinner E, Keane T, Marreaud S, Collette S, Sylvester R: A prospective, randomised EORTC intergroup phase 3 study comparing the oncologic outcome of elective nephron-sparing surgery and radical nephrectomy for low-stage renal cell carcinoma. Eur Urol 2011;59:543-552.

14 Huang WC, Elkin EB, Levey AS, Jang TL, Russo P: Partial nephrectomy versus radical nephrectomy in patients with small renal tumors: is there a difference in mortality and cardiovascular outcomes? J Urol 2009; 181:55-62.
15 MacLennan S, Imamura M, Lapitan MC, Omar MI, Lam TB, Hilvano-Cabungcal AM, Royle P, Stewart F, MacLennan G, MacLennan SJ, Dahm P, Canfield SE, McClinton S, Griffiths TR, Ljungberg B, N'Dow J: Systematic review of perioperative and quality-of-life outcomes following surgical management of localised renal cancer. Eur Urol 2012;62:1097-1117.

16 Martín OD, Bravo H, Arias M, Dallos D, Quiroz Y, Medina LG, Cacciamani GE, Carlini RG: Determinant factors for chronic kidney disease after partial nephrectomy. Oncoscience 2018;5:13-20.

17 Marconi L, Desai MM, Ficarra V, Porpiglia F, Van Poppel H: Renal preservation and partial nephrectomy: patient and surgical factors. Eur Urol Focus 2016;2:589-600.

18 Praga M, Hernandez E, Herrero JC, Morales E, Revilla Y, Diaz-Gonzalez R, Rodicio JL: Influence of obesity on the appearance of proteinuria and renal insufficiency after unilateral nephrectomy. Kidney Int 2000; 58:2111-2118

19 Malcolm JB, Bagrodia A, Derweesh IH, Mehrazin R, DiBlasio CJ, Wake RW, Wan JY, Patterson AL: Comparison of rates and risk factors for developing chronic renal insufficiency, proteinuria and metabolic acidosis after radical or partial nephrectomy. BJU Int 2009; 104:476-481.

20 Benítez Mendes AC, Pardo VL, Sinclair ME, Ocantos J: Use of renal score in the preoperative stratification of tumours. Update in radiology. Rev Argentina Radiol 2017;81:28-38.

21 Kriegmair MC, Mandel P, Moses A, Lenk J, Rothamel M, Budjan J, Michel MS, Wagener N, Pfalzgraf D: Defining renal masses: comprehensive comparison of RENAL, PADUA, NePhRO, and C-Index Score. Clin Genitourin Cancer 2017;15:248-255. 